7 Kevin Walsh ${ }^{1}$, Christopher J. White ${ }^{2,3}$, Kathleen McInnes ${ }^{4}$, John Holmes ${ }^{5}$, Sandra Schuster ${ }^{6}$, Harald

\title{
Natural hazards in Australia: storms, wind and hail
}

8 Richter $^{7}$, Jason P. Evans ${ }^{8}$, Alejandro Di Luca ${ }^{8}$, Robert A. Warren ${ }^{9}$

$1 *$ School of Earth Sciences, University of Melbourne, Australia

2 School of Engineering and ICT, University of Tasmania, Australia

3 Antarctic Climate and Ecosystems Cooperative Research Centre, University of Tasmania,

Australia

4 CSIRO Marine and Atmospheric Research, Australia

5 JDH Consulting, Mentone, Australia

6 Consultant, Sydney, Australia

77 Australian Bureau of Meteorology, Melbourne, Australia

8 Climate Change Research Centre \& ARC Centre of Excellence for Climate System Science,

UNSW, Australia

9 Monash University, Australia

*Corresponding author's address: Kevin Walsh, School of Earth Sciences, University of Melbourne 3010 Victoria, Australia. kevin.walsh@unimelb.edu.au 


\section{Abstract} 32 4

Current and potential future storm-related wind and hail hazard in Australia is reviewed. Confidence in the current incidence of wind hazard depends upon the type of storm producing the hazard. Current hail hazard is poorly quantified in most regions of Australia. Future projections of wind hazard indicate decreases in wind hazard in northern Australia, increases along the east coast and decreases in the south, although such projections are considerably uncertain and are more uncertain for small-scale storms than for larger storms. A number of research gaps are identified and recommendations made. 

335 4

\section{Introduction}

Natural hazards associated with storms, such as severe wind and large hail, cause significant economic damage and social dislocation across Australia. For example, the high winds from Cyclone Tracy (1974) caused an estimated A\$2 billion dollars in damage (1999 dollars; BTE 2001). Similarly, the insured cost of the 1999 Sydney hailstorm was estimated to be A\$1.7 billion in 1999 dollars (RMS 2009).

Despite the severity of the impacts wrought by storms, there are limited reliable observed data for some types of storms and associated hazards, particularly for the estimation of current wind hazard from thunderstorms (section 2.2) and hail (section 2.3). Moreover, projections of future storm characteristics have important uncertainties associated with them (section 4), while for hail, projection studies have been few (section 4.2). Nevertheless, important progress has been made. To summarise the latest knowledge and understanding of Australian storms, this paper reviews the current scientific literature on the assessment, causes, observed trends and future projected changes of storm hazard in Australia, with a specific focus on severe wind and hail hazard. The meteorological causes of severe wind and hail are first outlined, including their geographical distribution and methods of measurement, followed by observed trends. Future projections of these hazards are then detailed, along with the uncertainties in these projections, concluding with principal findings and some key open knowledge gaps and recommendations on future research priorities.

\section{Understanding wind and hail hazards}

\subsection{Storms that produce severe wind and hail}


"Storms" are here defined as weather systems that produce severe wind and hail but their

occurrence varies from region to region in Australia. In the mid-latitude regions of Australia's south, extreme winds are produced by severe thunderstorms and intense extra-tropical cyclones (ETCs), including their cold fronts. In the tropical regions of Australia, the largest contribution to wind hazard is from tropical cyclones (TCs), with wind hazard from these systems occasionally extending as far south as northern New South Wales (NSW) on the east coast and the Perth region in the west. In addition to wind hazard, TCs can cause storm surge (which is discussed in the companion coastal extremes paper, McInnes et al. (this issue)), flooding (which is similarly discussed in Johnson et al. (this issue)), landslide damage and tornadoes. The east coast of Australia from eastern Victoria (VIC) to southeastern Queensland (QLD) is subject to heavy rain, strong winds and large waves resulting from coastal low pressure systems that develop from a variety of weather systems (Speer et al. 2009). Generally referred to as East Coast Lows (ECLs), they cause a significant amount of damage along the east coast each year. In the alpine areas, mountain wave activity can lead to destructive winds on the downwind side of a ridge line under specific meteorological conditions (Reinecke and Durran 2009), for example, at Thredbo valley in 2014 (pers. comm. including site inspection; http://www.abc.net.au/catalyst/stories/4117934.htm).

2 Severe thunderstorms are convective systems defined by the Australian Bureau of Meteorology to be accompanied at least one of the following:

- Hailstones with a diameter of $2 \mathrm{~cm}$ or more

- Wind gusts of $90 \mathrm{~km} / \mathrm{h}$ or greater

- $\quad$ Flash flooding

- Tornadoes

Storms that produce large hail and/or damaging winds (including tornadoes) typically form in environments with significant thermodynamic instability and strong vertical wind shear (large 
changes in wind speed and direction with height). In Australia, the highest incidence of these systems is reported along the central and southern portions of the east coast (e.g. Allen et al. 2011, their Fig. 1a).

\subsection{Assessing current wind hazard}

The strongest wind hazard is in the tropical regions of the country, where TCs occur. For the design and assessment of buildings and structures, the region of influence of TCs is deemed to be coastal strips as far south as $27^{\circ} \mathrm{S}$ on both the Western Australia (WA) coastline, and on the east QLD coast (Standards Australia 2011). Based on the predicted effects of global warming (see section 4), these boundaries may need to be extended further south (Holmes 2008, 2011; Kossin et al. 2014)

Since the 1960s, the 'standard' method of making estimates of return periods for high wind speeds (i.e. for low annual probabilities of exceedence) has been based on recorded or 'historical' data, to which the Type I Extreme, or Gumbel, probability distribution has been fitted (e.g. Coles et al. 2001). This distribution suffers from the disadvantage that it produces extreme values with no upper limit: that is, continually increasing values of wind speed are generated as the return period increases. From the 1990s onward, the less conservative Type III Extreme Value Distribution has been used in Australia (Standards Australia 2011). This distribution produces predictions that slowly asymptote to a (very) high upper limit, which is physically more realistic.

In Australia, the only recorded wind data that can realistically be used to assess extreme wind speeds is the daily maximum gust that has been recorded by the Bureau of Meteorology since the 1940s, mostly at the standard height of 10 metres above flat, open country. These data are not temporally homogeneous. In the 1990s, the conversion from the Dines anemometer (approximately 0.2 second gusts) to Automatic Weather Stations (AWS) with cup anemometers (digitally filtered to 3-second gusts) resulted in a discontinuity in the database, with the later AWS extreme gusts being on average $10-20 \%$ lower than the earlier values, although conversion factors between the two have 
104

105 2

3

406

6 107 8 908 11 1209 13 14

been established (Holmes and Ginger 2012; Miller et al. 2013). These issues have affected efforts to develop high quality surface wind data sets (Jakob 2010).

In many parts of Australia, high gusts are generated by more than one storm type - for example, in the Sydney area both short duration thunderstorms and longer duration, synoptic-scale events, such as ECLs, can produce high gusts. It is advisable, and good practice, for gusts produced by different storm types to be separately analysed when carrying out extreme value analysis for a site.

Clearly, making estimates of extreme wind speeds at return periods of the order of hundreds of years (which is usual for the design of structures against collapse or overturning - the so-called 'ultimate limit states') will result in significant sampling errors, when data for an individual recording station is only available for 30-40 years. This can be partially alleviated in practice by combining data from several stations in the same general location into a single 'super-station' (but see Palutikof et al. 1999 for a discussion of the limitations of this methd).

Nevertheless, at locations where the occurrence of storms of a certain type are infrequent - for example TCs at Cairns, QLD - the use of recorded gust data to make long-term return period estimates will give very unreliable results. An alternative approach has been developed since the 1970s, based on simulating thousands of storms with the characteristics of those in the general area, for example the Coral Sea in the case of Cairns. These methods generally consist of a combination of probabilistic components (e.g. for the central pressure of TCs) and deterministic components (e,g. for the wind field model associated with a tropical storm) (e.g. Harper 1999). A similar approach is adopted for the impact of smaller storms such as thunderstorm downbursts or tornadoes on physically large systems such as a transmission line several hundred kilometres in length (e.g. Oliver et al. 2000).

The ability to estimate the current hazard accurately varies between storm types. Wind and hail hazard from severe thunderstorms can be difficult to estimate over a large region. The main source 
of data for severe thunderstorm incidence is reports provided by a network of observers, many of whom are members of the general public. This record is spatially and temporally inhomogeneous (Allen et al. 2011). The size of severe thunderstorms, typically less than $50 \mathrm{~km}$ in diameter, means that they are not well observed in the sparsely populated regions of Australia. Meaningful

climatologies based on severe thunderstorm reports have been constructed in other parts of the globe but these are typically in regions of higher population and data density (e.g. Doswell et al. 2005). Allen and Karoly (2014) circumvented this underreporting problem by instead examining the incidence of larger-scale meteorological conditions conducive to the generation of severe thunderstorms (that is, favourable "storm environments"), based on previous similar approaches such as that of Brooks et al. (2003). They calibrated their severe thunderstorm thresholds with available reports of severe thunderstorms in densely populated regions. A limitation of this technique is that it estimates only the potential for formation of severe thunderstorms and is not an accurate estimate, since their technique relies on probability assessment based on sparse data.

Observations of lightning can also provide insight into the occurrence of hazardous convective weather, including damaging winds. Studies from the USA have demonstrated a clear link between an increase in lightning flash count (so-called lightning "jumps") and the onset of severe weather (e.g. Schultz et al. 2011). However, to date, lightning data in Australia have only been used to examine the distribution of all thunderstorms (Dowdy and Kuleshov 2014) and not specifically severe storms.

Tornadoes are a particularly violent form of severe winds that are produced mostly by supercell thunderstorms, long-lived thunderstorms that have their own small cyclonic circulation ("mesocyclone"). Supercell tornadoes have been studied extensively in U.S. through two dedicated field campaigns (VORTEX1; Rasmussen et al. 1994; VORTEX2; Wurman et al. 2012) and many observational and numerical studies. In Australia, some tornado case studies have been published (e.g., Hanstrum et al. 2002; Richter 2007), but the composition of a meaningful tornado climatology 
153 is still a work in progress, as it involves the painstaking collection and evaluation of disparate

154 information sources such as newspaper articles (Allen and Allen 2016).

2

3

ECLs are phenomena with relatively small spatial scales (often smaller than TCs) and short

lifetimes (Holland et al. 1987), and their pressure centres may develop or intensify offshore making them difficult to study using standard in situ observations. It has been known for some time that ECLs produce large precipitation and wind events on the east coast of Australia (e.g. Holland et al. 1987; McInnes et al. 1992; Hopkins and Holland 1997; Mills et al. 2010). Moreover, ECLs have the capacity for rapid intensification (Holland et al. 1987), and thus have been found to satisfy the "Bomb" or rapid intensification criterion (a central pressure fall of $24 \mathrm{hPa}$ in 24 hours) of Sanders and Gyakum (1980).

The specific way in which ECLs are defined and the methodology used to identify and track these cyclones varies considerably. The earlier work of Hopkins and Holland (1997) employed an objective technique that combined wind and rain signatures typical of ECLs, as verified by comparison with surface charts. Recent studies have used approaches based on expert judgment (Speer et al. 2009), and various automated techniques that either track low pressure systems (Pepler and Coutts-Smith 2013; Browning and Goodwin 2013; Di Luca et al. 2015) or identify favourable conditions for their formation (Dowdy et al. 2013b). Pepler et al. (2014) investigated the differences in ECL characteristics obtained using three different identification methods, finding that the methods concur for relatively large and strong ECL events (including those producing high winds) but diverge for smaller ECLs. While few studies have focused specifically on the wind hazard associated with ECLs, the various measures used to characterize the intensity of ECLs, such as the pressure gradient around the centre or the maximum cyclonic vorticity, are related to the wind and hence changes in these intensity measures are expected to reflect changes in the wind. 
At higher latitudes, for ETCs and their associated cold fronts, wind hazard can be estimated

reasonably well from Bureau of Meteorology wind data, as ETCs are more common than TCs.

Higher return period winds from ETCs have considerably lower accuracy, however.

\subsection{Assessing current hail hazard}

Current estimates of the hail hazard in Australia are available only from the Bureau of

Meteorology's severe-storm archive (SSA; http://www.bom.gov.au/australia/stormarchive/). As previously discussed, this dataset suffers from large uncertainties associated with population bias and changing reporting practices, making it unsuitable for assessing the climatology of hail storms on a national scale. However, for local regions with high population density, valuable information can be extracted. Using an expanded dataset for NSW, Schuster et al. (2005) were able to assess various characteristics of hail occurrence in the eastern part of the state, including seasonal and diurnal cycles, geographical variability, and the distribution of maximum hailstone size. Soderholm et al. (2015) identified preferred regions for hailstorm occurrence in southeast QLD based on a 17year radar-based climatological study.

Meteorological radars provide a three-dimensional view of storms within a few hundred kilometres of their location at high spatial and temporal resolution. Numerous methods have been proposed for diagnosing hail occurrence at the surface based on the reflectivity measured aloft by singlepolarization radars (e.g. Amburn and Wolf 1997, Schuster et al. 2006). The hail detection algorithm (HDA) currently employed by the National Weather Service (NWS) in the USA uses the method of Witt et al. (1998) to provide real-time estimates of the probability of severe hail (POSH) and the maximum expected size of hail (MESH). This approach was also used by Cintineo et al. (2012) to generate a multi-year radar-based climatology of severe hail for the contiguous United States. A similar effort is currently being undertaken for the Brisbane region by one of the authors (R. Warren). Future upgrades to the operational radar network in Australia - in particular, the 
incorporation of dual-polarization measurements - should allow for a more accurate assessment of the hail hazard (e.g. Heinselman and Ryzhkov 2006).

While radars offer the most direct method of identifying hail remotely, their coverage in many countries, including Australia, is limited to major population centres. Thus, assessment of the hail hazard over larger geographic domains demands alternative methods. Two which have shown promise in other countries are the detection of overshooting cloud tops (OTs) using satellite-derived brightness temperatures (e.g. Bedka 2011) and the observation of rapid increases in lightning activity from ground-based sensors (e.g. Schultz et al. 2009). Both features are proxies for a strong/strengthening convective updraught and have been found to frequently precede the occurrence of severe weather (including hail) at the surface. Until very recently, geostationary satellite images for Australia were available only once per hour, making the identification of shortlived OTs unfeasible. However, with the new Himawari-8 satellite, temporal sampling has now been increased to 10 minutes (JMA 2014).

A final, more indirect method for inferring hail occurrence may be to use relevant environmental parameters (e.g. convective available potential energy, CAPE), derived from observations or reanalyses. So far in Australia, this type of analysis has only been performed for generic severe thunderstorms (Allen and Karoly 2014) and only provides an approximate estimate of severe thunderstorm conditions. However, recent research has demonstrated the potential to extend the approach to specific hazards such as hail (Allen et al. 2015).

\section{Observed trends}

\subsection{Observed trends in severe wind - large-scale storms}

To date, much of the analysis of observed trends in extreme wind hazard has been focused on trends in individual meteorological phenomena rather than wind per se. Trend analyses that have been 10 
224 performed on winds in the Australian region have given inconclusive results. McVicar et al. (2008)

225 showed positive trends in maximum winds for an average of a limited number of Australian stations

2 326 5 227 7 228 10 1229 12 13 1230 15

over the period 1975-2006. The later study of Troccoli et al. (2012) indicated some trends in the $90^{\text {th }}$ percentile of winds, similar to trends in mean winds, but also that the trends seemed to be sensitive to the height of the anemometer. Based on their analysis, Troccoli et al. (2012) concluded that recent changes in Australian wind speeds due to changes in circulation appeared unlikely.

To understand the causes and uncertainties of future projections of extreme wind changes, it is important to understand the causes and trends of the storms producing them. Trends in TC winds are often difficult to estimate due to the rather short reliable record of TC numbers and intensities. For example, in remote ocean areas, many TCs were simply undetected before the satellite era (before about 1970) and it was not until the advent of routine geostationary satellite monitoring around 1980 that a systematic estimation of TC intensity could be obtained. One way to address this issue is to analyse only land-based data. Callaghan and Power (2011) constructed a database of eastern Australian landfalling TC data, and found a substantial decrease in the incidence of severe TCs making landfall in this region since the late nineteenth century. Dowdy (2014) show a similar decrease in TC numbers, based on analysis of satellite observations and after removing the effects of ENSO variations on TC numbers.

For ECLs, there is large inter-annual and inter-decadal variability in their frequency (e.g. Hopkins and Holland 1997; Di Luca et al. 2015; Ji et al. 2015) and a lack of any statistically significant trend in recent decades (Pepler et al. 2014). In the mid-latitudes during the late 20th century, the Southern Hemisphere ( $\mathrm{SH}$ ) midlatitude jet and associated ETC storm track moved polewards and intensified (Fyfe 2003). This is consistent with Australian-focused studies that find a reduction in rainfallproducing systems over southwestern Australia since 1975 (Hope et al. 2006) and a reduction in storm numbers in southeastern Australia (Alexander and Power 2009) since the mid-19 $9^{\text {th }}$ century. Another mid-latitude wind hazard is caused by TCs that have moved into the mid-latitudes and 
249 become ETCs (e.g. Sinclair 2002; Ramsay et al. 2012). These storms can affect southern Australia 250 and New Zealand, causing large rainfall events and storm surge.

\subsection{Observed trends in severe thunderstorm winds and hail}

Analysis of trends in severe thunderstorm incidence from reports is highly problematic due to the sparse and inhomogeneous nature of these records (e.g. Kuleshov et al. 2002). As a result, environment-based studies, similar to those described above, have been used as a basis for trend estimation and projections. The recent reviews of Kunkel et al. (2013) and Brooks (2013) discuss this issue in detail for the United States and elsewhere, finding no significant current trends in severe thunderstorm environments.

Trend analysis has been performed in Europe using networks of hail measuring devices ("hailpads" e.g. Hermida et al. 2013) but such long-term records do not exist in Australia. Therefore reliable trend analysis has not been performed and remains a significant gap in our knowledge.

\section{Future projections}

\subsection{Projections of severe wind - large-scale storms}

Projections of future wind hazard have primarily focused on projections of different storm types.

Current issues for global predictions of TCs are summarized in (for example) Walsh et al. (2015).

This section briefly summarizes the current state-of-the-art of these methods but focuses more on the predictions of changes of these hazards in the Australian region.

In a warmer world, theoretical and modeling results suggest an expansion of the tropical regions, which in principle suggests weaker wind shear in the subtropical region and thereby poleward 12 
271 expansion in the region influenced by tropical cyclones, of the typical latitudes of formation of

272 ECLs, and of the latitudes where TCs typically become extratropical (e.g. Kossin et al. 2014). A

2

373 5 274 7 8 275 11

similar poleward movement in the main extratropical storm track is suggested (Chang et al. 2012),

although consensus on the precise mechanism for this is lacking at present.

The main tool for the prediction of future TC wind hazard is the climate model. The main limitation of this tool for TC prediction is that studies have shown that to simulate realistic numbers of TCs, climate models typically require resolutions usually higher than $25 \mathrm{~km}$, finer than are routinely used (Strachan et al. 2013). Even finer resolutions are often required to generate a realistic distribution of TC wind speeds. This limitation has spurred the development of regional climate modelling approaches, whereby finer resolution is only applied over a restricted region of the globe (Knutson et al. 2015). The best such models typically are run at horizontal resolutions finer than $10 \mathrm{~km}$ and are now able to generate a realistic TC wind distribution.

A consistent prediction of such modelling approaches is an increase in the maximum intensity of TCs combined with a decrease in their total numbers (Christensen et al. 2013). The recent results of Knutson et al. (2015) indicate substantial decreases in total TC numbers in the Australian region, typically around $30 \%$ or more towards the end of the 21 st century, especially off the northeast coast. Even larger declines in the Australian region are projected in numbers of the most intense SaffirSimpson category 4 and 5 storms, typically around 50\%. A projected decrease in future numbers of very intense TCs is important because one of the uncertainties in previous work has been whether the combination of predicted decreased numbers of TCs, combined with an increase in their maximum intensities, would lead to a decrease or an increase in future intense TC numbers in the Australian and adjacent South Pacific regions. The results of Knutson et al. (2015) suggest future decreases in extreme TC wind hazard in a warmer world in these regions, but this result will need to be made more robust through further improvements in modelling and theoretical techniques, due in part to the large basin-to-basin variability in this result in their study (their Table 3). For instance, 
based on analytical techniques, Holland and Bruyere (2014) suggested that there is unlikely that a decrease in numbers of intense storms will occur in this basin.

The main limitations of climate model projections of TC incidence are twofold. First, due to the infrequent and sometimes unpredictable formation and track of TCs, a very lengthy climate record is required to produce a statistically stable incidence of TC climatology, typically thousands of years (e.g. McInnes et al. 2003). Thus estimates of the likely changes in incidence need to be averaged over regions to construct climate change scenarios, rather than being extracted directly from the output of climate models. Secondly, the same uncertainties that plague all climate model projections affect our confidence in the future projections of TCs: uncertainty regarding future projections of the atmospheric concentration of greenhouse gases (due to wide variations in predictions of future economic conditions) and uncertainties regarding the accuracy of the climate models themselves.

As for TCs, ECL projections are generally based on results from climate model simulations.

However, an additional issue associated with ECLs is related to their identification, which has been shown to be strongly sensitive to the horizontal resolution of the input data in both reanalysis (Di Luca et al. 2015) and GCMs (Dowdy et al. 2013c). Dowdy et al. (2013a) and Dowdy et al. (2013c) used a vorticity measure based on a small number of GCM projections and found a $30 \%$ decrease in future ECL frequency by the end of the 21 st century. They associated this change with a decrease of 8 to $25 \%$ in heavy rainfall events on the eastern seaboard.

Some studies have used finer resolution dynamical downscaling of GCMs to better capture the full distribution of ECLs (Hemer et al. 2011; Ji et al. 2015). Hemer et al. (2011; 2013) used a regional climate model to downscale three GCMs to $60 \mathrm{~km}$ resolution. They found that mean wind speeds tend to decrease between latitudes $30 \mathrm{~S}$ and $40 \mathrm{~S}$, with little change in the 99th percentile of wind speed. Ji et al. (2015) applied the vorticity measure proposed by Dowdy et al. (2013b) to a 12 member ensemble of 50-km resolution regional climate projections created by downscaling four 
321 GCMs with three RCMs within the NARCliM project (Evans et al. 2014). They found an overall

B22 decrease in ECL frequency by 2070, particularly in winter.

2

3

323 6

While this collection of studies does not represent a comprehensive analysis of projected future changes in ECLs, they do consistently predict a decrease in storm activity, particularly in winter. However, previous studies have not explicitly examined wind speed changes produced by the most intense ECLs. Figure 1 shows the composite wind fields derived from ECLs developing near the east coast of Australia (see the white rectangle in Figure SM1 in the Supplementary Material) that produce maximum wind speeds of at least $20 \mathrm{~ms}^{-1}$ according to the NARCliM ensemble (12 50-km resolution RCM simulations). In both present and future climates, seasonal differences in the wind fields are clear, with summer ECLs tending to produce higher wind speed maxima compared to winter ECLs which produce a broader area of high wind speeds further from the low centre. While these results agree with previous studies in terms of projecting an overall decrease in the frequency of winter ECLs, they suggest no change in the frequency of the most intense and highest wind producing ECLs in winter and an increase in the frequency in summer. Hence the wind hazard associated with these intense events is likely to increase in the future (see the Supplementary Material).

Further south, the overall effect of greenhouse gas forcing on ETCs during the 21 st century is complex because climate models indicate changes that would have opposing effects on ETC activity including, for example, a reduction of the equator-to-pole temperature gradient near the surface but enhanced gradients aloft (Lim and Simmonds 2009). Grieger et al. (2014) find a reduction in the total number of Southern Hemisphere ETCs but an increase in the number of strong ETCs particularly over the southeastern Australian region, in a multimodel ensemble of CMIP3 climate models. These changes are consistent with findings of a general reduction in future extreme wind speed along much of the southern coastline except for Tasmania in the winter months 
345 (McInnes et al. 2011). For extratropically-transitioning TCs, studies in this region of the effect of

B46 climate change are currently lacking.

2

3

Studies have constructed scenarios of the effect of climate change on wind hazard and then applied these scenarios for the estimation of future wind hazard in Australia. Wang et al. (2013) construct current climate estimates of both cyclone and non-cyclone wind gust hazard in the Australian region by fitting a statistical model to wind speed observations from anemometers. They then applied climate change scenarios, encompassing a wide range of uncertainty and including scenarios of both increases and decreases in TC intensities and frequencies, to estimate the changes in these statistical distributions. For some of the scenarios that they examined, changes in wind speed return periods would occur that would exceed current design standards in a number of coastal tropical locations in Australia. It is noted that because of the wide range in predictions of future cyclone incidence in this region, this is a highly uncertain outcome.

\subsection{Projections of severe thunderstorm wind and hail}

Projections of severe thunderstorm occurrence are limited: Brooks (2013) states in his recent review that this question remains open. Recently, Allen et al. (2014) used an environments-based approached to suggest an increase in severe thunderstorm incidence in south-east Australia, although with a wide range of uncertainty. For hail, Braganza et al. (2013) reviewed this topic and noted that the few available studies indicate increases in hail frequency in the southeastern regions and near Sydney.

\section{Conclusions and research gaps}

Current hazard for various storm types has not been reliably estimated, due to either inadequate length of data record or spatial gaps. These issues are particularly pronounced for hail records but satellite observations have considerable potential to address these issues. The projections of future wind hazard in the Australian region differ from region to region. For example, in the tropics, recent 16 
369

B70 2 371 5 372 7 373 10 11

evidence suggests that extreme wind hazard may decrease, although confidence in this prediction is

low, whereas increases are possible in the east coast region subject to ECLs. Further south, a

general reduction in extreme wind speed return periods may occur. All of these projections are

accompanied by considerable uncertainty but such uncertainty has the potential to decrease with

improvements in modelling techniques.

Identifiable research gaps vary between storm type. For TCs, while improvements have been made in the confidence of projections of future wind hazard, further improvements in climate model simulations of TCs are needed, through increased resolution and better representation of model physics. Similar arguments can be made for ECLs. The effect of a warmer climate on extratropical former TCs is a potential area of research. ETCs are better simulated because of their larger size, so there the main research issue is whether the large-scale climate itself is well simulated. This issue is of course important as well for all types of storms.

For severe thunderstorms, remote-sensing platforms offer the potential to greatly improve our understanding of the associated hail and wind hazard in Australia. These include the GPATS lightning-detection network (www.gpats.com.au), the new Himawari-8 satellite, and the Bureau of Meteorology's radar network, which will soon begin an upgrade to dual-polarisation. Work is needed to investigate the applicability to Australian storms of existing methods of severe-weather detection based on these technologies (e.g. Heinselman and Ryzhkov 2006, Schultz et al. 2009, Bedka 2011). Validation of these techniques will require a large number of high-quality direct observations of hail and damaging winds. Based on the success of the mPING citizen scientist project in the US (Elmore et al. 2014), it is suggested that a mobile-phone application for reporting severe weather would be an excellent way of obtaining these data while simultaneously engaging the general public with the atmospheric science community. Reports could additionally be solicited directly from the public (Ortega et al. 2009) or collected in targeted field campaigns (Heymsfield et al. 2014). 


\section{B95 Acknowledgements}

2

3

4

396 The authors would like to thank their respective institutions for supporting this work. J.P. Evans is 6

397 supported by funding from the NSW Office of Environment and Heritage funded NSW/ACT 8 1398 11 139

13

14

15
1600

17

18

19

20

21

22

23

24

25

26

27

28

29

30

31

32

33

34

35

36

37

38

39

40

41

42

43

44

45

46

47

48

49

50

51

52

53

54

55

56

57

58

59

60

61

62

63 


\section{References}

3 Allen JT, Allen ER (2016) A review of severe thunderstorms in Australia. Atmos Res 178-179:

4

5 6 $347-366$

Allen JT, Karoly DJ, Mills GA (2011) A severe thunderstorm climatology for Australia and associated thunderstorm environments. Aust Meteorol Oceanogr J 61: 143-158

Allen JT, Karoly DJ (2014). A climatology of Australian severe thunderstorm environments 19792011: interannual variability and ENSO influence. Int J Climatol 34: 81-97

Allen JT, Karoly DJ, Walsh KJ (2014) Future Australian severe thunderstorm environments, Part II: The influence of a strongly warming climate on convective environments. J Climate 27: $3848-3868$

Allen JT, Tippett MK, Sobel AH (2015) An empirical model relating U.S. monthly hail occurrence to large-scale meteorological environment. J Adv Model Earth Sys 7: 226-243

Alexander LV, Power S (2009) Severe storms inferred from 150 years of sub-daily pressure observations along Victoria's "Shipwreck Coast". Austr Meteorol Oceanogr J 58:129-133

Amburn SA, Wolf PL (1997) VIL Density as a hail indicator. Wea Forecast 12: 473-478

Bedka KM (2011) Overshooting cloud top detections using MSG SEVIRI Infrared brightness temperature and their relationship to severe weather over Europe. Atmos Res 99: 175-189

Braganza K, Hennessy K, Alexander L, Trewin B (2013) Changes in extreme weather. In: Christoff P (ed) Four Degrees of Global Warming: Australia in a Hot World, pp 33-60

Brooks HE (2013) Severe thunderstorms and climate change. Atmos Res 123: 129-138

Brooks HE, Lee JW, Craven JP (2003) The spatial distribution of severe thunderstorm and tornado environments from global reanalysis data. Atmos Res 67: 73-94

Browning SA, Goodwin ID (2013) Large-scale influences on the evolution of winter subtropical maritime cyclones affecting Australia's east coast. Mon Wea Rev 141: 2416-2431 
Bureau of Transport Economics (2001) Economic costs of natural disasters in Australia. Report no. $103,170 \mathrm{pp}$.

Callaghan J, Power SB (2011) Variability and decline in the number of severe tropical cyclones making land-fall over eastern Australia since the late nineteenth century. Clim Dyn 37: 647662

Chang EK, Guo Y, Xia X (2012) CMIP5 multimodel ensemble projection of storm track change under global warming. J Geophys Res Atmos 117 (D23)

Christensen JH et al (2013) Climate phenomena and their relevance for future regional climate change. In Stocker TF et al. (eds): Climate Change 2013: The Physical Science Basis. Contribution of Working Group I to the Fifth Assessment Report of the Intergovernmental Panel on Climate Change (IPCC AR5) Cambridge University Press 2013, Cambridge, United Kingdom and New York, NY, USA, pp 1217-1308.

Cintineo JL, Smith TM, Lakshmanan V, Brooks HE, Ortega KL (2012) An objective highresolution hail climatology of the contiguous United States. Wea Forecast 27: 1235-1248

Coles S, Bawa J, Trenner L, Dorazio P (2001). An introduction to statistical modeling of extreme values (Vol. 208). London: Springer.

Di Luca A, Evans JP, Pepler A, et al. (2015) Resolution sensitivity of cyclone climatology over eastern Australia using six reanalysis products. To appear in J Climate

Doswell III CA, Brooks HE, Kay MP (2005) Climatological estimates of daily local nontornadic severe thunderstorm probability for the United States. Wea Forecast 20: 577-595

Dowdy AJ (2014) Long-term changes in Australian tropical cyclone numbers. Atmos Sci Letters 15: 292-298, doi: $10.1002 / \operatorname{as} 12.502$

Dowdy AJ, Kuleshov Y (2014). Climatology of lightning activity in Australia: spatial and seasonal variability. Aust Meteorol Oceanogr J 6: 9-14

Dowdy AJ, Mills GA, Timbal B, et al (2013a) Understanding rainfall projections in relation to extratropical cyclones in eastern Australia. Aust Meteorol Oceanogr J 63:355-364 
Dowdy AJ, Mills GA, Timbal B (2013b) Large-scale diagnostics of extratropical cyclogenesis in eastern Australia. Int J Climatol 33:2318-2327. doi: 10.1002/joc.3599

Dowdy AJ, Mills GA, Timbal B, Wang Y (2013c) Changes in the risk of extratropical cyclones in eastern Australia. J Climate 26:1403-1417. doi: 10.1175/JCLI-D-12-00192.1

Evans JP, Ji F, Lee C, et al (2014) Design of a regional climate modelling projection ensemble experiment - NARCliM. Geosci Model Dev 7:621-629. doi: 10.5194/gmd-7-621-2014

Fyfe JC (2003) Extratropical southern hemisphere cyclones: Harbingers of climate change? J Climate 16:2802-2805

Grieger J, Leckebusch G, Donat M, Schuster M, Ulbrich U (2014) Southern Hemisphere winter cyclone activity under recent and future climate conditions in multi-model AOGCM simulations. Int J Climatology 34:3400-3416

Hanstrum BN, Mills GA, Watson A, Monteverdi JP, Doswell III CA (2002) The cool-season tornadoes of California and southern Australia. Wea Forecast 17: 705-722

Harper BA (1999) Numerical modelling of extreme tropical cyclone winds. J Wind Eng Industr Aerodyn 83: 35-47

Heymsfield AJ, Giammanco IM, Wright R (2014) Terminal velocities and kinetic energies of natural hailstones. Geophys Res Letters 41: 8666-8672.

Heinselman PL, Ryzhkov AV (2006) Validation of polarimetric hail detection. Wea Forecast 21: $839-850$

Hemer MA, McInnes KL, Ranasinghe R (2013) Projections of climate change-driven variations in the offshore wave climate off south eastern Australia. Int J Climatol 33:1615-1632. doi: 10.1002/joc. 3537

Hemer MA, McInnes KL, Ranasinghe R (2011) Climate and variability bias adjustment of climate model-derived winds for a southeast Australian dynamical wave model. Ocean Dyn 62:87104. doi: 10.1007/s10236-011-0486-4 
67 Hermida L, Sánchez JL, López L, Berthet C, Dessens J, García-Ortega E, Merino A (2013)

Jakob D (2010) Challenges in developing a high-quality surface wind-speed data-set for Australia. Aust Meteorol Oceanogr J 60:227-236

Ji F, Evans JP, Argueso D, et al (2015) Using large-scale diagnostic quantities to investigate change in East Coast Lows. Clim Dyn 45: 2443-2453. doi: 10.1007/s00382-015-2481-9

Climatic trends in hail precipitation in France: spatial, altitudinal, and temporal variability. Sci World J doi: 10.1155/2013/494971

Holland G, Lynch A, Leslie L (1987) Australian east-coast cyclones .1. Synoptic overview and case-study. Mon Wea Rev 115:3024-3036

Holland GJ, Bruyere C (2014) Recent intense hurricane response to global climate change. Clim Dyn 42: 617-627. doi: 10.1007/s00382-013-1713-0.

Holmes JD (2008 and 2011) Impact of climate change on design wind speeds in cyclonic regions. JDH Consulting and Australian Building Codes Board, June 2008 and June 2011 (revised edition).

Holmes JD, Ginger JD (2012) The gust wind speed duration in AS/NZS 1170.2, Aust J Struct Eng 13: $207-217$

Hope PK, Drosdowsky W, Nicholls N (2006) Shifts in the synoptic systems influencing southwest Western Australia. Clim Dyn 26:751-764

Hopkins LC, Holland G (1997) Australian Heavy-rain days and associated east coast cyclones: 1958-92. J Climatol, 10: 621-635 doi: 10.1175/1520-0442

JMA (2014) New geostationary meteorological satellites - Himawari-8/9. Available online at http://www.jma.go.jp/jma/kishou/books/himawari/2014_Himawari89.pdf.

Knutson TR, Sirutis JJ, Zhao M, Tuleya RE, Bender M, Vecchi GA, Villarini G, Chavas D (2015) Global projections of intense tropical cyclone activity for the late $21^{\text {st }}$ century from dynamical downscaling of CMIP5/RCP4.5 scenarios. J Climate 28: 7203-7224 
Kossin JP, Emanuel KA, Vecchi GA (2014) The poleward migration of the location of tropical cyclone maximum intensity. Nature 509: 349-352.

Kuleshov Y, de Hoedt G, Wright W, Brewster A (2002) Thunderstorm distribution and frequency in Australia. Aust Meteorol Mag 51: 145-154

Kunkel KE, Karl TR, Brooks H, Kossin J, Lawrimore JH, Arndt D, Wuebbles D (2013) Monitoring and understanding trends in extreme storms: State of knowledge. Bull Amer Meteorol Soc 94: $499-514$

Lim E-P, Simmonds I (2009) Effect of tropospheric temperature change on the zonal mean circulation and SH winter extratropical cyclones. Clim Dyn 33:19-32

McInnes KL, Leslie LM, McBride JL (1992) Numerical simulation of cut-off lows on the Australian east coast: sensitivity to sea-surface temperature. Int J Climatol 12:783-795

McInnes KL, Erwin TA, Bathols JM (2011) Global Climate Model projected changes in $10 \mathrm{~m}$ wind speed and direction due to anthropogenic climate change. Atmos Sci Letters 12:325-333. doi: 10.1002/as1.341.

McInnes KL, Walsh KJE, Hubbert GD, Beer T (2003) Impact of sea-level rise and storm surges on a coastal community. Nat Haz 30: 187-207

McVicar TR, Van Niel TG, Li LT, Roderick ML, Rayner DP, Ricciardulli L, Donohue R (2008). Wind speed climatology and trends for Australia, 1975-2006: Capturing the stilling phenomenon and comparison with near-surface reanalysis output. Geophys Res Letters, 35

Miller CA, Holmes JD, Henderson DJ, Ginger JD, Morrison M (2013) The response of the Dines anemometer to gusts and comparisons with cup anemometers. J Atmos Ocean Tech 30: $1320-1336$

Mills GA, Webb R, Davidson NE, Kepert J, Seed A, Abbs D (2010) The Pasha Bulker east coast low of 8 June 2007. Centre for Australia Weather and Climate Research Tech. Rep. 23, 62 pp. 
111 Oliver SE, Moriarty WW, Holmes JD (2000) A risk model for design of transmission line systems against thunderstorm downburst winds. Eng Struct 22:1173-1179

113 Palutikof JP, Brabson BB, Lister DH, Adcock ST (1999) A review of methods to calculate extreme wind speeds. Meteorol Appl 6:119-132

Pepler A, Coutts-Smith A (2013) A new, objective, database of East Coast Lows. Aust Meteorol Oceanogr J 63:461-472

Pepler AS, Di Luca A, Ji F, et al (2014) Impact of identification method on the inferred characteristics and variability of Australian East Coast Lows. Mon Wea Rev 143:864-877. doi: 10.1175/MWR-D-14-00188.1

Ramsay HA, Camargo SJ, Kim D (2012) Cluster analysis of tropical cyclone tracks in the Southern Hemisphere. Clim Dyn 39: 897-917.

115 Rasmussen EN, Straka JM, Davies-Jones R, Doswell III CA, Carr FH, Eilts MD, MacGorman DR (1994) Verification of the origins of rotation in tornadoes experiment: VORTEX. Bull Amer Meteorol Soc 75: 995-1006

Reinecke PA, Durran DR (2009). Initial-condition sensitivities and the predictability of downslope winds. J Atmos Sci 66: 3401-341

Richter H (2007) A cool-season low-topped supercell tornado event near Sydney, Australia. Preprints, 33rd Conf. on Radar Meteorology, Cairns, Australia, Amer. Meteor. Soc. and Australian Bureau of Meteorology Research Center., P13A.16. [Available online at https://ams.confex.com/ams/pdfpapers/123550.pdf.]

Risk Management Solutions (1999) The 1999 Sydney hailstorm: 10-year retrospective. Available at http://riskinc.com/Publications/1999 Sydney Hailstorm.pdf.

Sanders F, Gyakum J (1980) Synoptic-dynamic climatology of the bomb. Mon Wea Rev 108:15891606 
122 Schultz CJ, Petersen WA, Carey LD (2009) Preliminary development and evaluation of lightning

Speer M, Wiles P, Pepler A (2009) Low pressure systems off the New South Wales coast and associated hazardous weather: establishment of a database. Aust Meteorol Oceanogr J 58:29-39 jump algorithms for the real-time detection of severe weather. J Appl Meteorol Clim 48: $2543-2563$

Schultz CJ, Petersen WA, Carey LD (2011) Lightning and severe weather: A comparison between total and cloud-to-ground lightning trends. Wea Forecast, 26: 744-755

Schuster SS, Blong RJ, McAneney KJ (2005) Relationship between radar-derived hail kinetic energy and damage to insured buildings for severe hailstorms in Eastern Australia. Atmos Res 81: 215-235

Schuster SS, Blong RJ, Speer MS (2006) A hail climatology of the Greater Sydney area and New South Wales, Australia. Int J Clim 25: 1633-1650

Sinclair MR (2002) Extratropical transition of southwest Pacific tropical cyclones. Part I: climatology and mean structure changes. Mon Weather Rev 130: 590-609

Soderholm J, McGowan H, Richter H, Walsh K, Weckwerth T, Coleman M (2015) The Coastal Convective Interactions Experiment (CCIE): Understanding the role of sea breezes in climatological hailstorm hotspots in Eastern Australia. Submitted to Bull Amer Meteorol Soc

Standards Australia (2011) Structural design actions. Part 2: Wind actions, Australian/New Zealand Standard, AS/NZS 1170.2:2011, Standards Australia, Sydney, NSW.

Strachan J, Vidale PL, Hodges K, Roberts M, Demory M-E (2013) Investigating global tropical cyclone activity with a hierarchy of AGCMs: the role of model resolution. J Climate 26: 133-152, doi: 10.1175/JCLI-D-12-00012.1.

Troccoli A, Muller K, Coppin P, Davy R, Russell C, Hirsch AL ( 2012) Long-term wind speed trends over Australia. J Climate 25: 170-183 
145 Walsh KJE, Camargo SJ, Vecchi GA, et al. (2015) Hurricanes and climate: the U.S. CLIVAR $146 \quad$ working group on hurricanes. Bull Amer Meteorol Soc 96: 997-1017

147 Wang CH, Wang X, Khoo YB (2013) Extreme wind gust hazard in Australia and its sensitivity to $148 \quad$ climate change. Nat Haz 67: 549-567

149 Witt A, Eilts MD, Stumpf GJ, Johnson JT, Mitchell ED, Thomas KW (1998) An enhanced hail 150 detection algorithm for the WSR-88D. Wea Forecast 13: 386-303

151 Wurman W, Dowell D, Richardson Y, Markowski P, Rasmussen E, Burgess D, Wicker L, Bluestein 152 HB (2012) The second Verification of the Origins of Rotation in Tornadoes Experiment: VORTEX2. Bull Amer Meteorol Soc 93: 1147-1170

154

155 
(a)



(c)

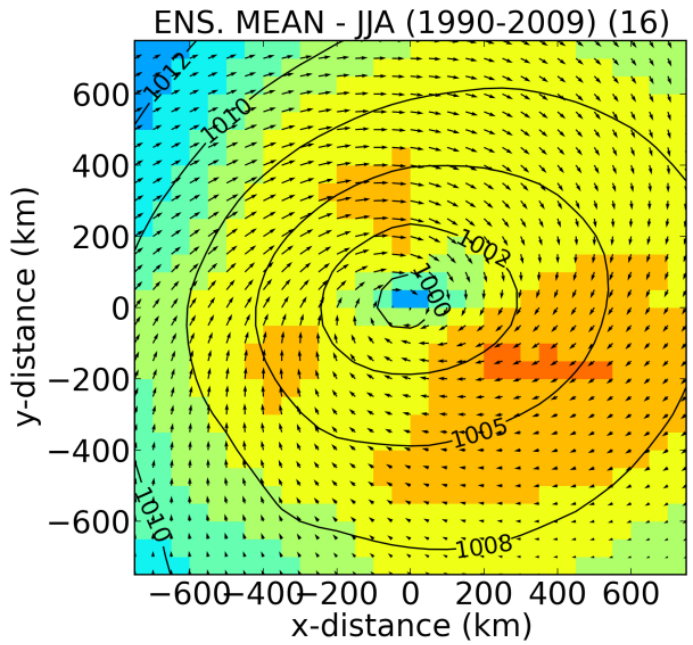

(b)

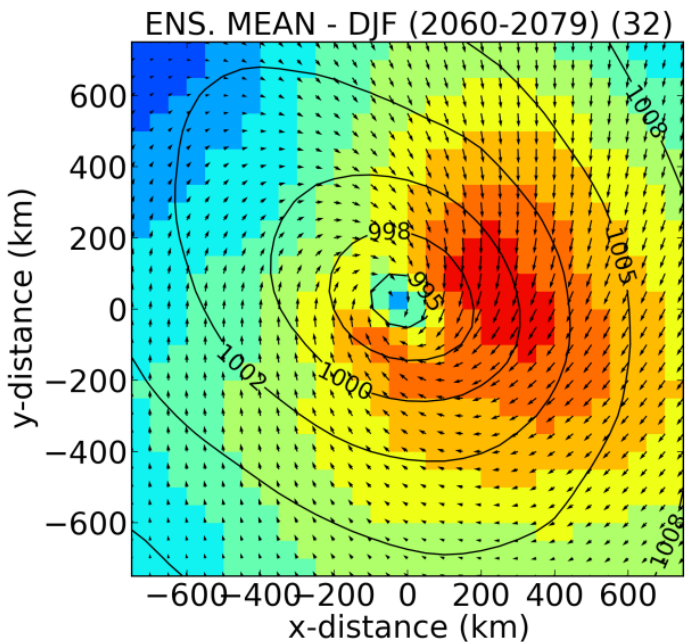

(d)

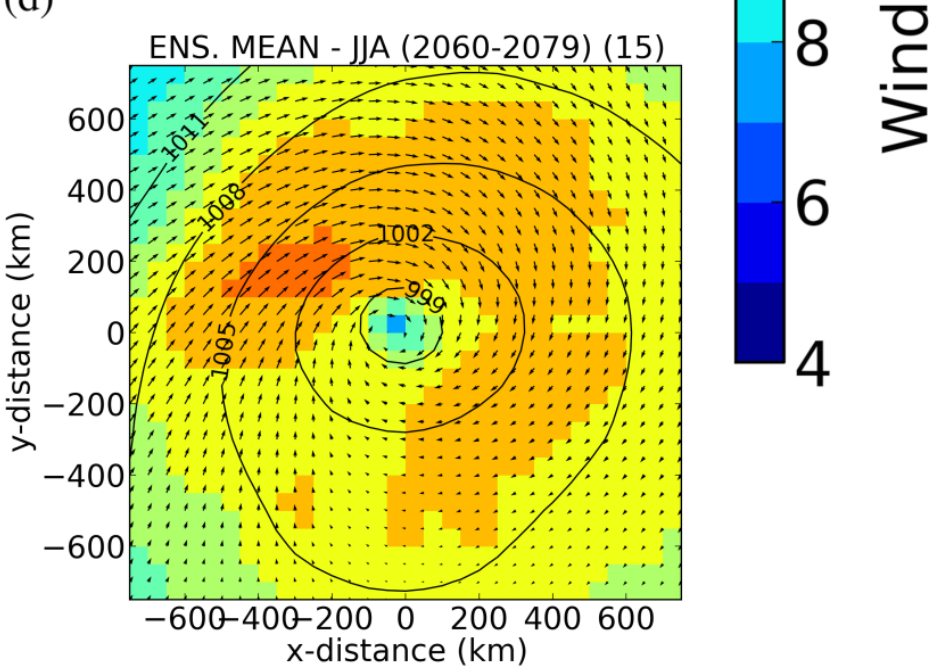

2 Figure 1: Ensemble composites of summer (DJF: top row) and winter (JJA: bottom row) ECLs

3 with a maximum wind speed greater than $20 \mathrm{~ms}^{-1}$ from the NARCliM ensemble for the recent past

4 (1990-2010: left column) and the future (2060-2079: right column). Coloured contours and vectors

5 indicate wind speed while solid line contours indicate the sea level pressure. The ensemble-mean

6 number of events within the composite is indicated to the top-right of each panel. 